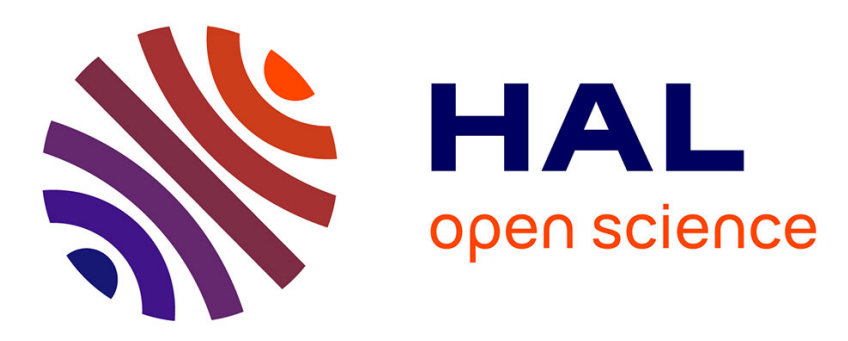

\title{
Novel heterostructured Ge nanowires based on polytype transformation
}

Laetitia Vincent, Gilles Patriarche, Geraldine Hallais, Charles Renard, Cyrille Gardès, David Troadec, Daniel Bouchier

\section{- To cite this version:}

Laetitia Vincent, Gilles Patriarche, Geraldine Hallais, Charles Renard, Cyrille Gardès, et al.. Novel heterostructured Ge nanowires based on polytype transformation. Nano Letters, 2014, 14, pp.48284836. 10.1021/nl502049a. hal-01058064

\section{HAL Id: hal-01058064 \\ https://hal.science/hal-01058064}

Submitted on 21 Oct 2021

HAL is a multi-disciplinary open access archive for the deposit and dissemination of scientific research documents, whether they are published or not. The documents may come from teaching and research institutions in France or abroad, or from public or private research centers.
L'archive ouverte pluridisciplinaire HAL, est destinée au dépôt et à la diffusion de documents scientifiques de niveau recherche, publiés ou non, émanant des établissements d'enseignement et de recherche français ou étrangers, des laboratoires publics ou privés. 


\title{
Novel Heterostructured Ge Nanowires Based on Polytype Transformation
}

\author{
Laetitia Vincent, ${ }^{*}, \dagger$ Gilles Patriarche, ${ }^{\S}$ Géraldine Hallais, ${ }^{\dagger \neq}$ Charles Renard, ${ }^{\dagger, \ddagger}$ Cyrille Gardès, ${ }^{\dagger, \ddagger}$ \\ David Troadec," and Daniel Bouchier ${ }^{\dagger, \ddagger}$ \\ ${ }^{\dagger}$ Univ. Paris-Sud, Institut d'Electronique Fondamentale, UMR 8622, Orsay F-91405, France \\ ${ }^{\ddagger}$ CNRS, Orsay F-91405, France \\ ${ }^{\S}$ CNRS, Laboratoire de Photonique et de Nanostructures, UPR20, Site Alcatel de Marcoussis, Route de Nozay, Marcoussis, F-91460, \\ France \\ "CNRS, Institut d'Electronique de Microélectronique et de Nanotechnologie, UMR 8520 Laboratoire Central, Cité Scientifique, \\ Avenue Poincaré, 59652 Villeneuve d'Ascq Cedex, France
}

\begin{abstract}
We report on a strain-induced phase trans-formation in Ge nanowires under external shear stresses. The resulted polytype heterostructure may have great potential for photonics and thermoelectric applications. $\langle 111 \nmid$ oriented Ge nanowires with standard diamond structure (3C) undergo a phase transformation toward the hexagonal diamond phase referred as the $2 \mathrm{H}$-allotrope. The phase transformation occurs heterogeneously on shear bands along the length of the nanowire. The structure meets the common phenomeno-logical criteria of a martensitic phase transformation. This point is discussed to initiate an on going debate on the transformation mechanisms. The process results in unprece-dented quasiperiodic heterostructures $3 \mathrm{C} / 2 \mathrm{H}$ along the $\mathrm{Ge}$ nanowire. The thermal stability of those $2 \mathrm{H}$ domains is also studied under annealing up to $650^{\circ} \mathrm{C}$ by in situ TEM.
\end{abstract}

KEYWORDS: Nanowires, phase-transformation, shear-stress, allotrope, heterostructure

$\mathrm{D}$ uring the past two decades, nanomaterials have become an exciting and rapidly expanding research area, and much of this excitement has arisen from the discovery of new physical phenomena and increased multifunctionality due to the so-called size-effects. Bottom-up nanowires are one of the most promising nanostructures that offer such multifunctional potential covering a broad range of nanotechnological developments in the strategic sectors of electronics, energy and biology. They adopt structural organizations very different from bulk materials or epitaxial films leading to unexpected properties and amazing applications. ${ }^{1-4}$ In particular, new polytype heterostructures, not realized in bulk with standard conditions, are made possible during VLS growth. Especially wurtzite/zincblende superlattices can be realized in III-V nanowires by adjusting growth parameters such as temperature, catalyst diameter and III/V flux ratio. ${ }^{5-7}$ The control of crystal structure in nanowires offers new possibilites in band gap engineering.

Concerning type-IV semiconductors, the hexagonal-diamond phase (equivalent wurtzite structure) was observed in silicon nanowires using copper catalysts. ${ }^{8}$ Another approach was to transfer a predifined wurtzite structure from a GaP nanowire to a Si shell. ${ }^{9}$ In bulk Si or Ge, this hexagonal-diamond phase was formed by phase transformation under high pressure and temperature conditions. ${ }^{10}$ Thus, thermomechanical treatment could be another way to obtain hexagonal-diamond structure in type-IV nanowires.

Several theoretical and experimental studies were carried out in recent years to understand how the mechanical properties are modified at the nanometer scale in order to control them for advanced new technologies. Most of the nanowires exhibit superior mechanical properties with decreasing diameter size: higher stiffness and larger yield stress. ${ }^{11-17}$ Simulations suggest a significant influence of crystallographic direction of the nanowires as well as side surface orientation. ${ }^{18,19}$ The sizedependent behaviors are often attributed to intrinsic surface stresses. $^{20-22}$ They induce substantial intrinsic compressive stress that can lead to spontaneous reorientations and even to phase transformations. ${ }^{23,24}$ Additionally, edges on free surfaces form high stress points and may act as preferential nucleation site for defects and/or shear failure. ${ }^{25}$ Thus, mechanisms of deformation (dislocation formation, slip, and twinning) can 
differ from bulk. This unique mechanical behavior can cause unprecedented structural reorganizations of atoms inducing the creation of novel functional materials and heterostructures.

In this Letter, we report on a strain-induced martensitic phase transformation in Ge nanowires. The hexagonal-diamond phase corresponding to the $2 \mathrm{H}$-allotrope is identified. The transformation results in an unprecedented heterostructure with quasiperiodic embedded $\mathrm{Ge}-2 \mathrm{H}$ nanodomains distributed all along the Ge nanowire. At last, we study the thermal stability of those domains with in situ TEM observations.

"Nanostructuration" Process. 〈111〉-oriented Ge NWs are synthesized using the VLS process with $\mathrm{Au}$ catalyst seeds (mean diameter of $30 \mathrm{~nm}$ ) obtained by dewetting on a $\langle 111\rangle-\mathrm{Si}$ substrate. The growth is performed by UHV-CVD with diluted digermane $\mathrm{Ge}_{2} \mathrm{H}_{6}\left(10 \%\right.$ in $\left.\mathrm{H}_{2}\right)$ under a pressure of $4 \mathrm{~Pa}$ at 320 ${ }^{\circ} \mathrm{C}$. After growth, the gold contamination is removed using $\mathrm{KI}: \mathrm{I}_{2}: \mathrm{H}_{2} \mathrm{O}$ etching during $10 \mathrm{~s}$. Then the nanowires are embedded in a hardening hydrogen silsesquioxane (HSQ) resist that is subsequently baked between 400 and $500{ }^{\circ} \mathrm{C}$. The HSQ used for the process is a flowable oxide known as FOX delivered by Dow Corning. This kind of resist was initially chosen with regards to its ability to be cured into $\mathrm{SiO}_{2}$-like films and to its technological characteristics: hardness, good behavior at temperature, good planarization, and especially its low viscosity, giving the ability to perfectly fill the gap between nanowires. The HSQ resist is then cured by thermal annealing to dissociate $\mathrm{Si}-\mathrm{H}$ bonds and form a silica film. These structure and chemical changes are accompanied by a densification and a shrinkage, which in turn involve a large intrinsic stress inside the film. In addition, during cooling the film experiences thermal stress due to different coefficients of thermal expansion between the silica film and the silicon substrate. Thus, at the end of the process a large residual stress (tensile) is expected. ${ }^{26,27}$ After baking the obtained $\mathrm{SiO}_{2}$ matrix is easily removed with a solution of HF:ethanol (1:10) leaving the nanowires free on the substrate. All the procedure steps are described in detail in the sketch of Figure 1.

Figure 2 compares general SEM views of as grown nanowires, embedded nanowires, and stripped processed nanowires. The different morphologies between as-grown nanowires and processed nanowires are evident: as-grown nanowires are first straight and smooth, but after the process, they exhibit a large and rough sawtooth structure, what we call a "nanostructuration" in the following description. Note that asgrown nanowires do not evidence a rough surface as we reported on Si nanowires nor gold spreading is observed along the nanowires (which has been previously demonstrated to be associated with the faceting of the surface). ${ }^{3}$ Numerous tests have been carried out to verify the occurrence of this structuration. First of all, we have checked the absence of nanostructuration just after spin coating, that is, without baking. It is also worth noting that for partially embedded nanowires, the structuration appears only within the embedded part (see Supporting Information) and not in the "free" top part of the nanowires. Then several baking parameters are tested by varying temperature, time, rate and gas atmosphere (see Table 1 for details). Three major heating techniques are tested and compared: a hot plate (limited to $250{ }^{\circ} \mathrm{C}$ ), a tubular furnace maintained at $500{ }^{\circ} \mathrm{C}$ under $\mathrm{N}_{2}$ atmosphere (i.e. preheated at the desired temperature when the samples are introcuced), and a rapid thermal anneal (RTA) furnace used under primary vacuum. First we have observed that the curing time is not a critical parameter. For a given temperature, the gas atmosphere

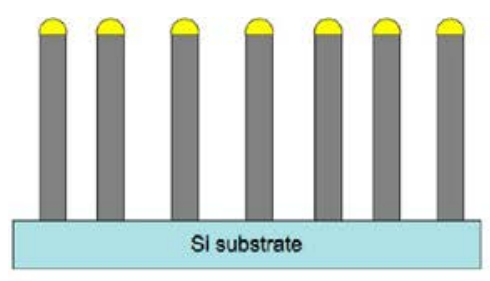

Ge nanowires are grown by UHV-CVD on $\mathrm{Si}$ substrate with Au catalysts

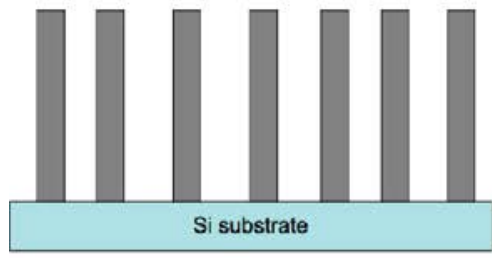

Au contamination is removed with a $\mathrm{KI}: \mathrm{I}_{2}: \mathrm{H}_{2} \mathrm{O}$ Rinced in ethanol and dryed with N2

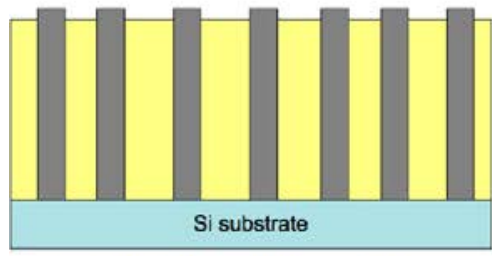

Spin coating of HSQ resist on nanowires

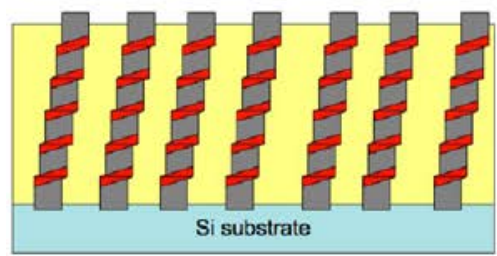

Baking of the HSQ resist, transformation into SiO,

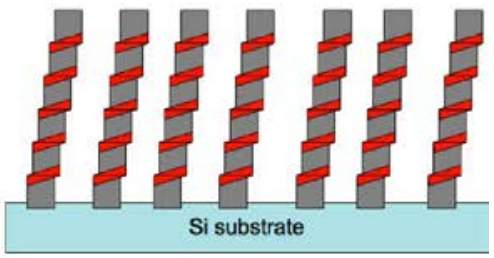

Removal of $\mathrm{SiO}_{2}$ with $\mathrm{HF}$ :ethanol

Figure 1. Sketch of the overall procedure developed for the structural transformation of $\mathrm{Ge}$ nanowires. Note that the process can be easily adapted to large surface wafers.

during curing seems to not play a major role in the process. The heating and cooling rates may have some influence according to the nanostructuration obtained at $300{ }^{\circ} \mathrm{C}$ with RTA, whereas no nanostructuration was observed at $320^{\circ} \mathrm{C}$ in a classical oven with slow rates. Finally, it appears that temperature has a greater influence than the other parameters. We have identified roughly a temperature threshold lying between 350 and $400{ }^{\circ} \mathrm{C}$ for the nanostructuration.

Phase Transformation. Therefore, the nanowires were analyzed by transmission electron microscopy (TEM) and energy-dispersive X-ray spectrometry (EDS) to study further the structuration and especially the crystallographic structure of those nanowires. For TEM, either FIB lamellas or spread nanowires were deposited on appropriate TEM grids. 

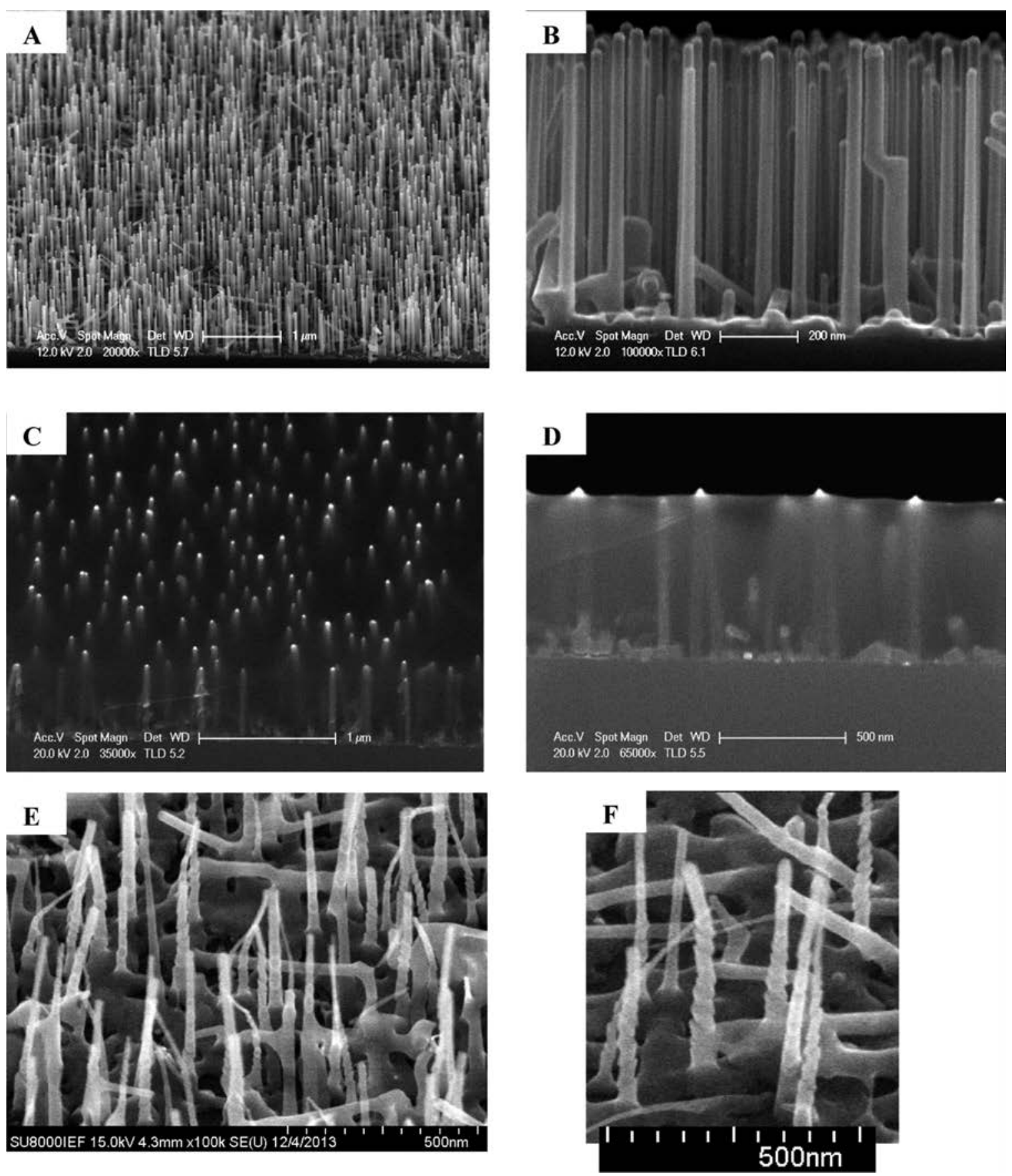

Figure 2. SEM views (tilted and cross section) of Ge nanowires at various steps of the process. (A and B) As-grown nanowires. Most of the nanowires are straight and $\langle 111\rangle$-oriented. Here, the length is around $650 \mathrm{~nm}$. (C and D) Nanowires embedded in a HSQ matrix. Gold clusters have previously been removed with KI:I2 etching. (E) Nanowires after removing the HSQ in a HF:ethanol solution. (F) Enlarged view of a processed nanowire exhibiting a sawtooth structuration.

Observations were performed using a Cs-corrected JEOL 2200FS operating at $200 \mathrm{kV}$.

Figures 3 and 4 show TEM micrographs of a processed nanowire. It exhibits a sawtooth shape with almost periodic shear bands. On each shear band, a nanodomain is observed, showing a different structure. EDS measurements were performed along the transformed nanowires to verify the composition of the transformed domains (see Supporting Information). Some fluctuations of $\mathrm{Ge}$ content are due to the presence of residual $\mathrm{SiO}_{2}$ clusters on the nanowire. However, we do not observe any significant difference between the $3 \mathrm{C}$ and $2 \mathrm{H}$ parts. Thus, we argue that the transformed domains are Ge domains.

On the HR-HAADF STEM micrograph of Figure 4B, we identify unambiguously the hexagonal-diamond phase corresponding to the $2 \mathrm{H}$-allotrope observed along the $[\overline{2} 110]$ zone axis. This structure differs from the cubic one only by the stacking sequence of the dumbbells (clearly seen on the micrograph) with $A B A B$ instead of $A B C A B C$ (see Figure 5). So, this structure is equivalent to wurtzite one. The $\mathrm{Ge}$ nanowire undergoes here a phase transformation that seems to 
Table 1. Data of Different Annealing Processes and the Occurrence of Nanowire Structuration

\begin{tabular}{|c|c|c|c|c|c|c|}
\hline annealing type & $\begin{array}{c}\text { temperature } \\
\left({ }^{\circ} \mathrm{C}\right)\end{array}$ & $\begin{array}{c}\text { time } \\
(\mathrm{min})\end{array}$ & atmosphere & $\begin{array}{l}\text { heating rate } \\
\left({ }^{\circ} \mathrm{C} / \mathrm{s}\right)\end{array}$ & $\begin{array}{c}\text { cooling rate } \\
\left({ }^{\circ} \mathrm{C} / \mathrm{s}\right)\end{array}$ & sawtooth structure \\
\hline no baking & & & & & & no \\
\hline hot plate & 100 & 2 & air & & & no \\
\hline hot plate & 100 & 10 & air & & & no \\
\hline hot plate & 100 & 45 & air & & & no \\
\hline hot plate & 250 & 2 & air & & & no \\
\hline oven & 320 & 45 & air & $<0.03$ & & no \\
\hline tubular furnace & 500 & 45 & $\mathrm{~N}_{2}$ & & & yes \\
\hline tubular furnace & 400 & 45 & $\mathrm{~N}_{2}$ & & & yes \\
\hline $\begin{array}{l}\text { tubular furnace after } 15 \text { days resting without } \\
\text { baking }\end{array}$ & 400 & 45 & $\mathrm{~N}_{2}$ & & & yes \\
\hline tubular furnace after hot plate @ $100{ }^{\circ} \mathrm{C}$ & 500 & 45 & $\mathrm{~N}_{2}$ & & & yes \\
\hline tubular furnace after hot plate @200 ${ }^{\circ} \mathrm{C}$ & 400 & 45 & $\mathrm{~N}_{2}$ & & & yes \\
\hline RTA & 300 & 15 & vacuum or air & 6 & 1.5 & very few and localized \\
\hline RTA & 400 & 15 & vacuum or air & 6 & 1.5 & yes \\
\hline RTA & 500 & 15 & vacuum or air & 6 & 1.5 & yes \\
\hline
\end{tabular}

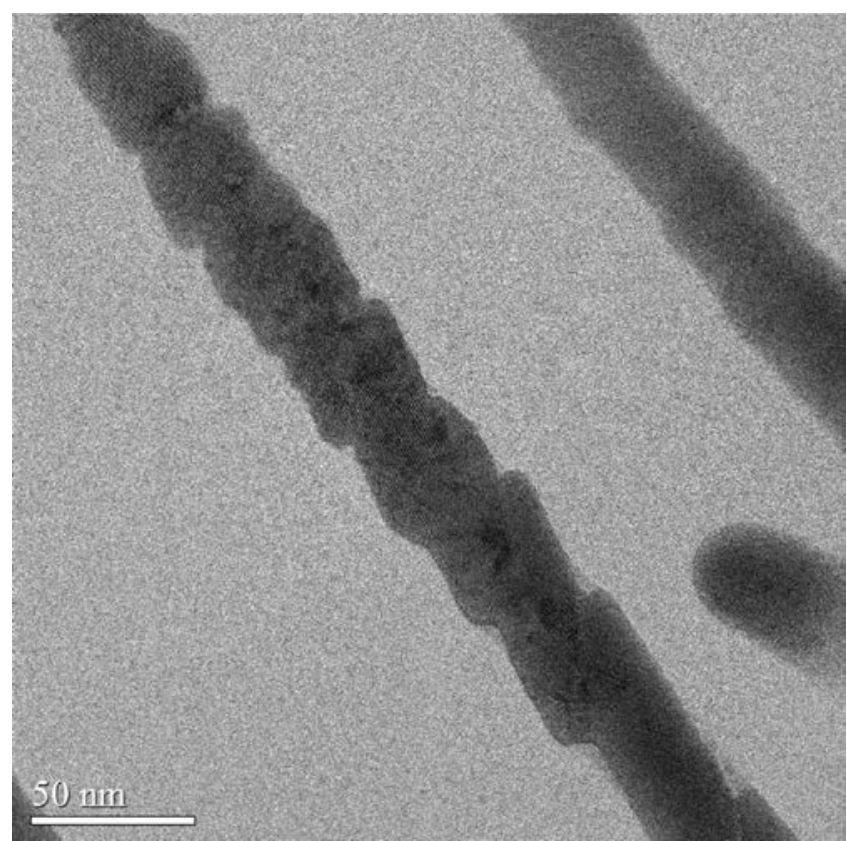

Figure 3. STEM micrograph of a heterostructured Ge nanowire. The nanowire exhibits a sawtooth shape with almost periodic steps. The nanowire is embedded in $\mathrm{SiO}_{2}$ and the TEM sample was prepared by FIB.

be strain-induced. And the process results in an allotrope heterostructured Ge nanowire.

It is important to mention that the habit plane of the nanodomains is most of the time along the $(001)_{3 \mathrm{C}}$ planes of the cubic surrounding nanowire, and interfaces between cubic and hexagonal domains are not exclusively of (001). On about 20 analyzed domains, we often index the (001) or (115) planes. Figure 6 shows HRTEM views of the same domain observed along two different directions using the $[1 \overline{1} 0]_{3 \mathrm{C}}$ and the $[2 \overline{11}]_{3 \mathrm{C}}$ zone axes. With the $[1 \overline{1} 0]_{3 \mathrm{C}}$ we observe the $2 \mathrm{H}$ domain standing along the $[\overline{2} 110]$ zone axis as described previously, whereas along the $[2 \overline{11}]_{3 \mathrm{C}}$ direction, the domain is not directly visible. We can instead see moiré fringes, significant of a superposition of both cubic and hexagonal lattices on the micrograph.
As shown on Figure 4B, the crystal orientations differ clearly from the usually $\{111\}$-twin boundary and $(111)_{3 \mathrm{C}} / /(0001)_{2 \mathrm{H}}$ interface of zinc-blende/wurtzite heterostructures. The orientation relationship of the transformed hexagonal domains with respect to the parent cubic nanowire are rather given by

$$
\left\{\begin{array}{l}
{[1 \overline{1} 0]_{3 \mathrm{C}} / /[\overline{2} 110]_{2 \mathrm{H}}} \\
(110)_{3 \mathrm{C}} / /(0001)_{2 \mathrm{H}}
\end{array}\right.
$$

However, a small angle can be noticed between both planes $(110)_{3 \mathrm{C}}$ and $(0001)_{2 \mathrm{H}}$. For instance in Figure $4 \mathrm{~B}$ the angle is of $2.5^{\circ}$. It is measured up to $8^{\circ}$ on other nanowires. Finally, a misorientation of the $3 \mathrm{C}$ areas appears between both sides of a $2 \mathrm{H}$ nanodomain. The image in Figure $4 \mathrm{~A}$ is processed with the GPA software to get the lattice rotation. Two reflections are selected $g=[111]$ and $g=[11 \overline{1}]$ in the Fourier transform to calculate the phase images and the $x$ direction is taken perpendicular to (111) planes. The $\mathrm{R}_{x y}$ rotation map is shown in Figure 7. The variation of color between both sides of a $2 \mathrm{H}$ nanodomain indicates an in-plane rotation of the lattice fringes with respect to a reference taken in the middle of the cubic area. The green area corresponds to the $\mathrm{Ge}-3 \mathrm{C}$ region taken as the reference. The blue area is rotated of about $5^{\circ}$ clockwise, and the red-yellow zone shows an anticlockwise rotation of $6^{\circ}$. In the $3 \mathrm{C}$ area the rotation is not homogeneous. A larger rotation is generally evidenced toward the tip of the area at the surface of the nanowire.

Bulk crystalline germanium is known to exhibit various allotropic phase transitions as a function of pressure and temperature. ${ }^{27-30,10}$ Among the most documented transitions, cubic diamond phase Ge-I transforms into the metallic $\beta$-tin phase Ge-II under hydrostatic compression conditions above $10 \mathrm{GPa}^{31}$ then toward the simple hexagonal phase at $75 \mathrm{GPa}$ and toward the double hexagonal close-packed polymorph at $102 \mathrm{GPa}^{29}$ The decompression leads mainly to a metastable tetragonal phase referred as Ge-III (ST12 structure) that transforms back to the cubic structure. ${ }^{31,32}$ We have also observed Ge-III by indentation of amorphous films. ${ }^{33}$ Another metastable phase Ge-IV is likely to occur depending on the unloading conditions. ${ }^{34}$ At room temperature, Ge-IV is very unstable and transforms into the hexagonal diamond structure $\mathrm{Ge}-\mathrm{V}$ corresponding to the $\mathrm{Ge}-2 \mathrm{H} .{ }^{34}$ Recently a renewed interest has come back regarding the formation of metastable Ge polytypes and, in particular, the pathways leading to the 


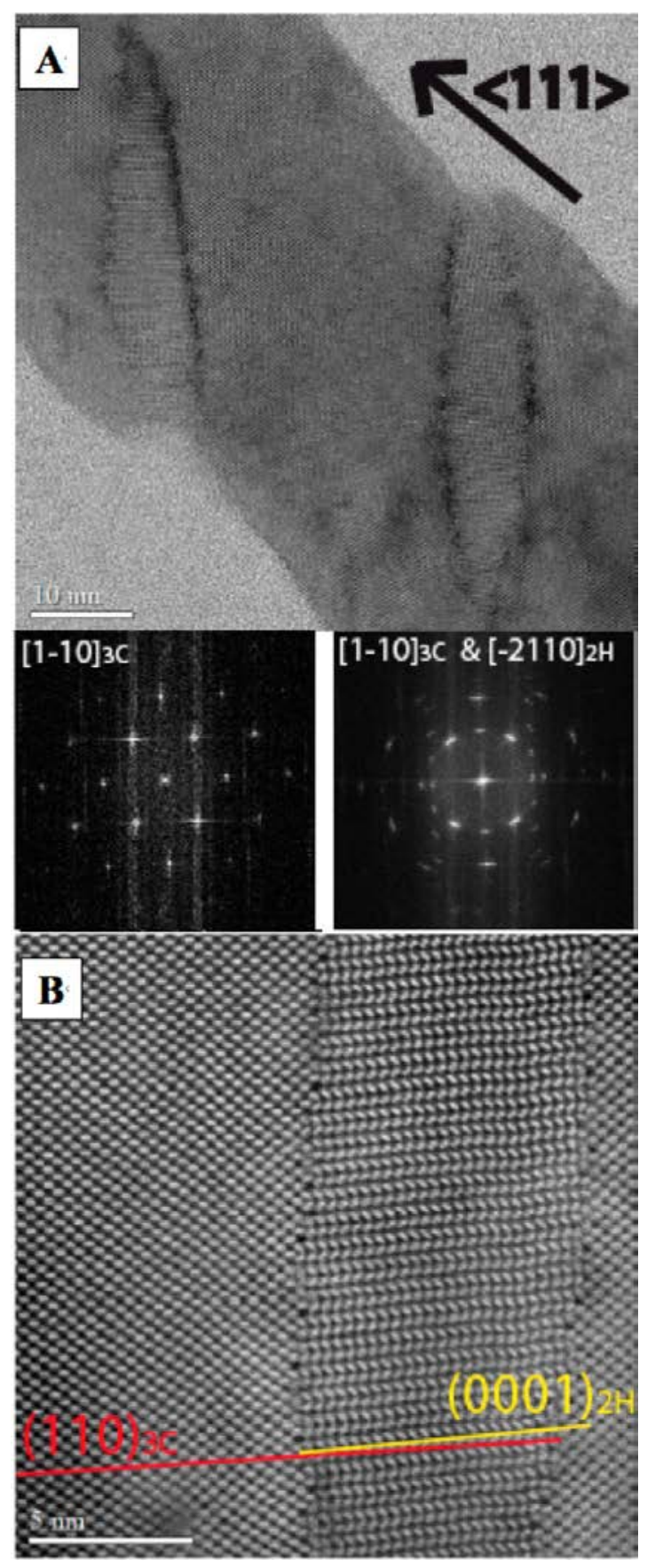

Figure 4. (A) High resolution bright-field STEM image of the heterostructured Ge nanowires. The image is taken along a [110] zone axis. Allotrope domains are located at each step visible in Figure 3. (B) HAADF-STEM image of one nanodomain from panel A. The $2 \mathrm{H}$ phase is clearly identifiable with a $A B A B A$ stacking sequence; see Figure 5 for more details. Fast Fourier transforms (FFT) are related to the micrograph A. New Bragg spots (on the right) with respect to the cubic matrix (on the left) are associated with the $2 \mathrm{H}$ phase. FFT evidence the following relation between both phases: $[1 \overline{1} 0]_{3 \mathrm{C}} / /$ $[2110]_{2 \mathrm{H}}$ and $(110)_{3 \mathrm{C}} / /(0001)_{2 \mathrm{H}}$.

various transformations. ${ }^{35}$ Important is to note the influence of shear stresses. Compared to hydrostatic loading, plastic shear generally reduces the transformation pressure significantly. ${ }^{31}$ Reference 35 also points out the effect of shear during unloading. Ge-2H seems to be produced only if the Ge-III is avoided (i.e., under hydrostatic release conditions).Thus, the
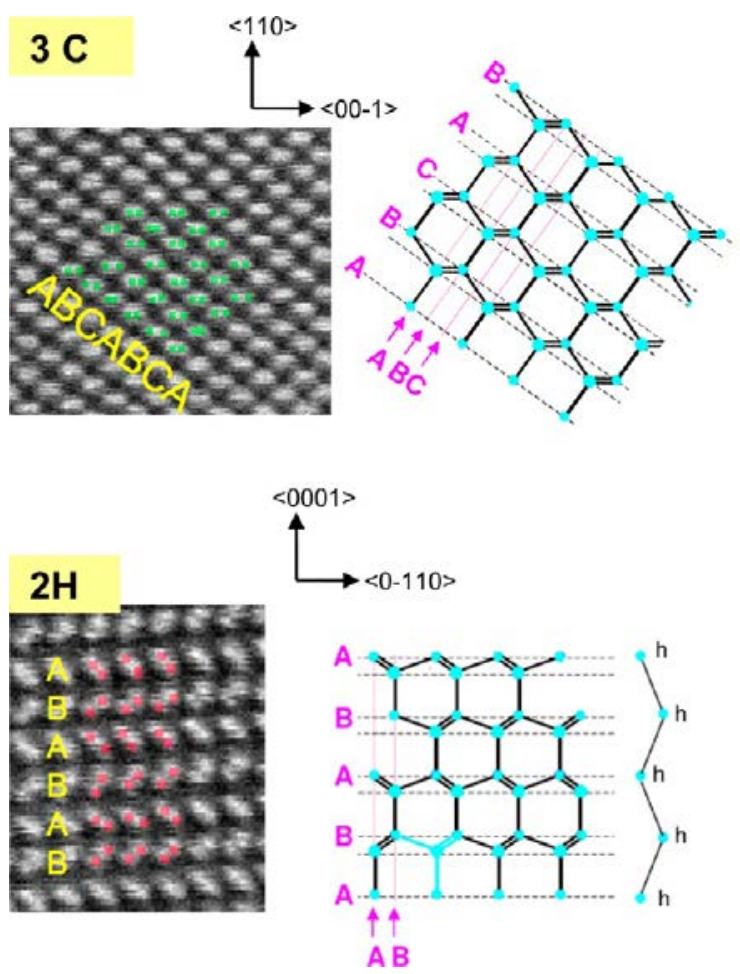

Figure 5. Enlarged views of Figure 4B (with the same orientations evidenced by the orthogonal spatial system) and the sketch of the stacking sequence respectively for $3 \mathrm{C}$ and $2 \mathrm{H}$ polytypes.
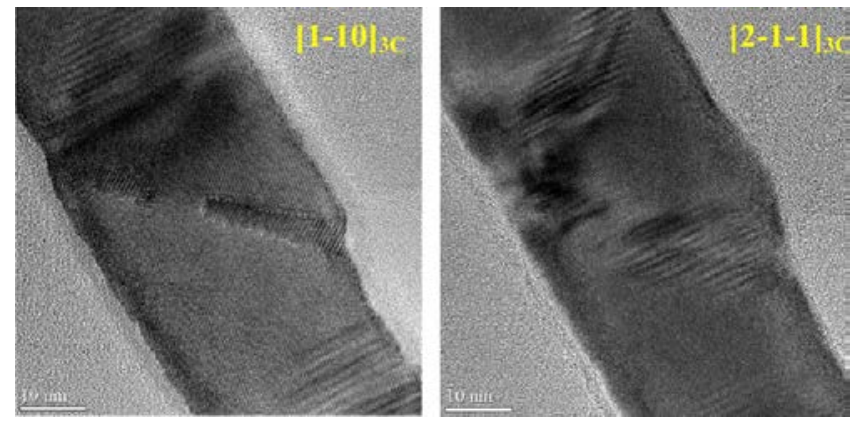

Figure 6. Nanowire with a Ge-2H nanodomain observed with two different zone axis, that is, $[1 \overline{1} 0]_{3 \mathrm{C}}$ and $[2 \overline{11}]_{3 \mathrm{C}}$.

transition pathways in Ge are still under debate. On the other hand, as for Si-IV ( $\mathrm{Si}-2 \mathrm{H})$, the transformation to $\mathrm{Ge}-\mathrm{V}$ was also reached under non hydrostatic loading conditions and high temperatures especially under hot indentation (around $400{ }^{\circ} \mathrm{C}$ ) or after explosive recrystallization with pulsed laser. ${ }^{36,37}$

We demonstrate this cubic to hexagonal-diamond transformation in nanowires for the first time. Phenomenologically, the present transformation bears similarities with the hot indentation and in the following we argue that it may be explained by considering the effects of external shear-stress induced by the thermal curing of the HSQ film on nanostructures. The thermal curing of the HSQ films roughly involves three stages, namely, (1) heating up, (2) isothermal annealing, and (3) cooling down stages. During heating and annealing, the densification accompanied by changes in structure and chemistry toward $\mathrm{SiO}_{2}$ involves a large intrinsic stress inside the films. During cooling, the film experiences thermal stress due to different coefficients of thermal expansion (CTE) between the film and the silicon substrate. Thus, at the 


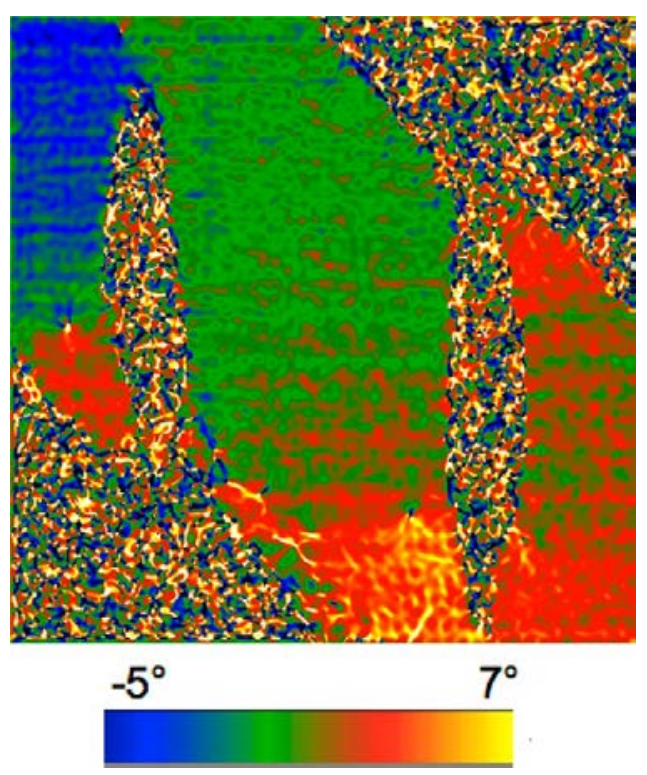

Figure 7. $\mathrm{R}_{x y}$ rotation map of lattice fringes obtained from Figure 4A.

end of the process a large residual stress is then expected. ${ }^{26}$ This point is supported by our observation of macroscopic cracks on few samples suggesting an in-plane tensile stress inside the film. An in-plane tensile stress of 80 to $100 \mathrm{MPa}$ is specified by the manufacturer Dow Corning and observed after thermal curing between 400 and $500{ }^{\circ} \mathrm{C} \cdot{ }^{27}$ However, it should be emphasize that the resulting stress should differ within the resulting composite film (nanowires- $\mathrm{SiO}_{2}$ ). Of course, the presence of nanowires may have influence on the global stress. Subsequently, the stress induced by the film upon the nanowires is difficult to assess. Probably, calculations using finite elements will be useful. Indeed this stress is likely the driving force of the phase transformation. Partially embedded nanowires (see Supporting Information) evidence the transformation only in the embedded part. In fact, the transformation of HSQ to silica can be performed either by thermal curing above $350{ }^{\circ} \mathrm{C}$ or under electron beam exposure. We have performed both. In the case of thermal curing at $500{ }^{\circ} \mathrm{C}$, we get the phase transformation in the nanowire, whereas using an electron or ion beam (FIB preparation), we observe some fractures (in Figure 8) but no phase transformation. It is worth noting that the fractures are located along shear bands with the same (001) planes previously observed for the thermally transformed domains. This experiment also evidence the influence of a threshold temperature required for the transformation. The threshold as mentioned in the first part is around $350{ }^{\circ} \mathrm{C}$. On one hand, this temperature is the required temperature for the chemical changes and densification of HSQ. On the other hand, it is also close to the temperature of the phase transformation performed under indentation as reported in the literature. ${ }^{36}$ Note that at room temperature, the indentation of Ge does not produce a phase transformation but rather leads to a plastic deformation by slip and twinning. ${ }^{38}$ Thus, our observations are quite similar to results reported on indentation-induced deformation and phase transformation in $\mathrm{Ge}$ (and $\mathrm{Si}$ ). As a first conclusion, both parameters that are thermal budget and stress must coexist to induce the phase transformation.

Of course, the involved mechanisms must be further investigated in the case of nanowires. Here, we draw some

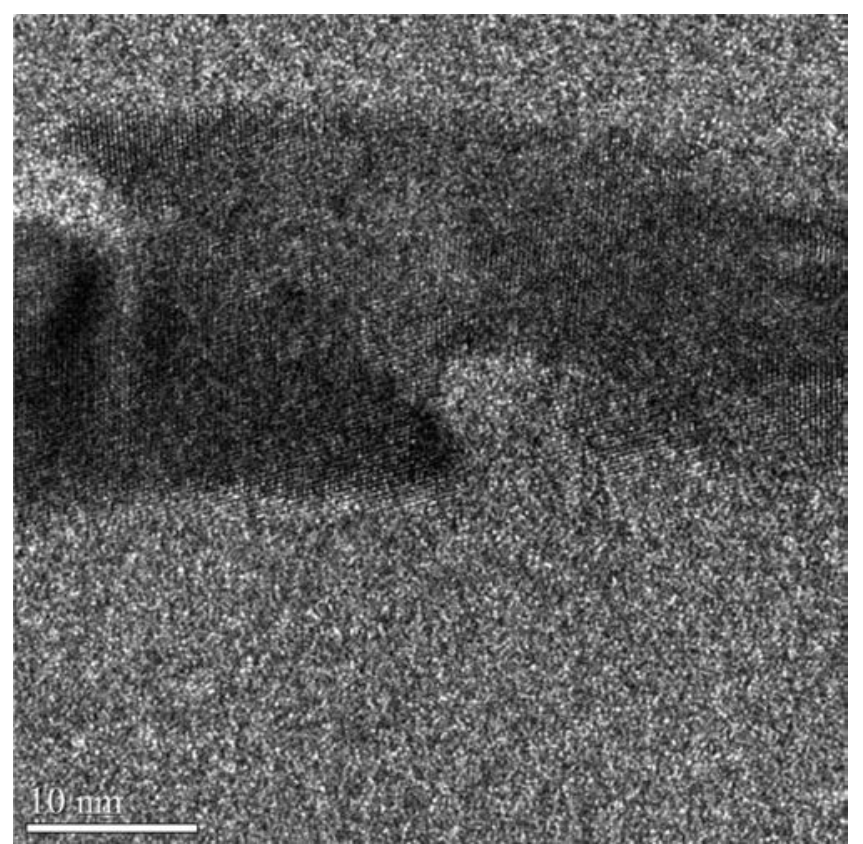

Figure 8. TEM micrograph of a fractured nanowire. The nanowire was embedded in a HSQ matrix. Then the HSQ was transformed under electron beam. No transformation is evidenced.

first considerations based on our observations and compared to previous observations reported in refs 36 and 37 and to further detailed studies of similar phase transformation in silicon.

The phase transformation toward the metastable $2 \mathrm{H}$ allotrope was indeed also observed in silicon upon indentation at temperature between 450 and $600{ }^{\circ} \mathrm{C} .{ }^{39,40}$ The deformed structure in the indentation periphery consists in numerous twin bands with $\{111\}$ twinning planes and in several ribbons of $\mathrm{Si}-2 \mathrm{H}$ phase with $\{115\}_{\text {matrix }}$ habit planes. The orientation relationship of $2 \mathrm{H}$ ribbons with the $3 \mathrm{C}$ matrix was identical to that of our nanodomains in nanowires except for the habit plane. Two major considerations came out:

(1) Effect of shear stress: high hydrostatic conditions do not lead to $2 \mathrm{H}$ structure while it is observed in the periphery of the indentation where shear stresses are predominant.

(2) Effect of temperature: at intermediate temperatures (400 to $600{ }^{\circ} \mathrm{C}$ ), extensive twinning is the predominant plastic deformation mode in $\mathrm{Si}$.

The indentation-induced phase transformation in both Ge and $\mathrm{Si}$ was ascribed to a martensitic transformation. A mechanism of stress relaxation during twin-twin intersection or secondary twin propagation was suggested by Dahmen et al $^{41}$ This transformation was, thus, commonly considered in diamond structure as one way for relieving the high stress in the region of twin intersection.

A martensitic transformation is generally defined as a distortive and diffusionless (or cooperative) transformation. In practice, it is indirectly recognized by two main crystallographic characteristics, that are (1) a shape change of the deformed region revealed by an upheaval of the surface (the surface of the transformed plate is tilted with respect to the rest of the surface) and (2) a precise and specific relationship between the parent structure and the new phase (typical habit plane and orientation relationship) due to the lack of diffusion. ${ }^{42-44}$ According to our observations, the Ge-2H domains in the deformed nanowires meet both criteria. Two 

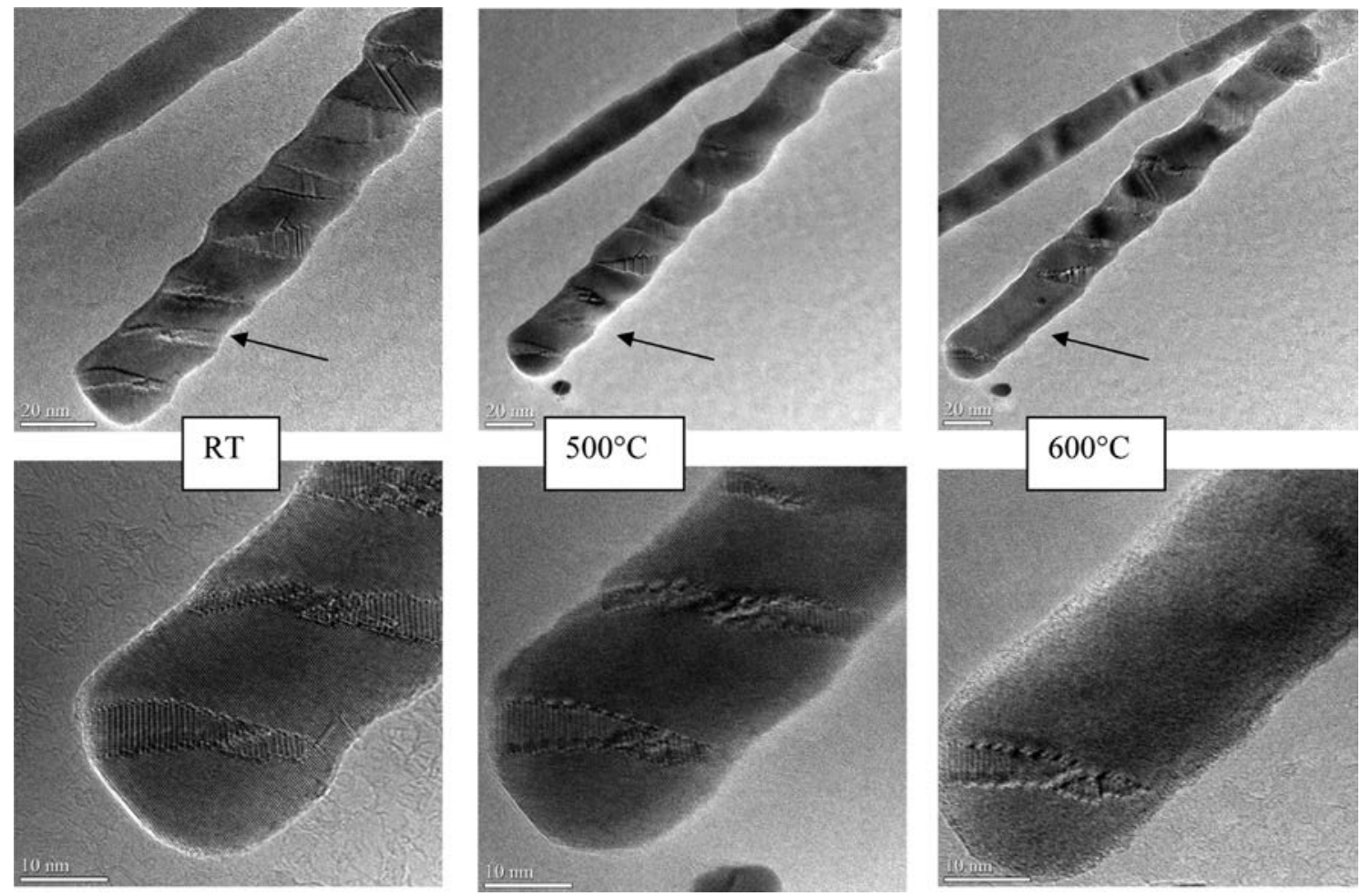

Figure 9. Evolution of some $2 \mathrm{H}$ nanodomains under successive thermal anneals during $10 \mathrm{~min}$ at $\mathrm{RT}, 500$, and $600{ }^{\circ} \mathrm{C}$. Note the disappearance of domains pointed with an arrow. $\mathrm{SiO}_{2}$ was removed by $\mathrm{HF}$ :ethanol etching and nanowires were dispersed on a carbon membrane.

kinds of process may lead to a martensitic transformation: either by quenching or under external high stress rates above the Ms temperature (i.e., start martensitic temperature), the first is referred as thermal-induced, whereas the second is straininduced and is particularly relevant in the case of hotindentation and of our findings. So, we do believe that the transformation we evidence in this paper presents the basic characteristics of a martensitic transformation. Nevertheless complementary experiments are required to check the diffusionless aspect and to study the nucleation and the growth. For such a goal, an attempt was made to perform in situ observation of the transformation. This experiment requires the obtention of TEM lamella consisting of embedded nanowires. Such TEM samples can be performed by FIB preparation. However, as shown in Figure 8 during the FIB preparation the $\mathrm{HSQ}$ is transformed and densified toward $\mathrm{SiO}_{2}$ under electron or ion beam and the nanowires are plastically deformed by slip and fractures. Finally, we did not observe any phase transformation during annealing of such nanowires.

Although the high density of twins was the condition of phase transformation under hot indention, in our case, few twins are observed in the nanowires. Moreover the model of twin-twin intersection was able to account for the $\{115\}$ habit plane of their observed $2 \mathrm{H}$ ribbons. Here, the domains are often bounded by (115) planes, but the domains are rather lying along shear bands parallel to the $\{001\}$ planes that do not correspond to usual slip or twinning plane. Thus, the mechanism differs from twin-twin intersection.

A probable size effect needs also to be discussed here. Obviously such transformation is not observed on films or bulk germanium with the same spin coating and thermal curing process. We believe that here size effects must play a role in order to lower the stress for the onset of transformation. Actually, recent experiments and molecular dynamics simu- lation have evidenced new deformation mechanisms at the nanoscale. The more leading feature described in those papers was the preferential nucleation of dislocations at the free surface especially on high stress points formed by steps, ${ }^{25,45}$ and activation of unusual slip planes is also predicted by simulations. ${ }^{46,47}$ The other important concept is the surface stress that is evoked to induce phase transformation in nanostructures. $^{23,48}$ This unique mechanical behavior can cause unexpected structural reorganizations of atoms. From Figure 3 and 4, it is remarkable that the transformed bands are oriented at $45^{\circ}$ from the nanowire axis, corresponding to the largest Schmidt factor (i.e., smallest required external stress) assuming a stress along the NW axis. It is clear that the martensitic transformation provides stress relief in the nanowire but the atypical behavior requires further investigation. Experiments are in progress to investigate a likely size effect. With our VLS growth conditions, we are limited to $60 \mathrm{~nm}$ in diameter for the obtention of well-oriented arrays of nanowires. And the transformation was observed up to this value. For larger diameters, a top-down approach is required which needs technological developments. At last, molecular dynamic simulations are necessary to understand the complex involved mechanisms at the onset of the transformation.

The developed process results in an unprecedented heterostructure with embedded $\mathrm{Ge}-2 \mathrm{H}$ domains distributed all along the $\mathrm{Ge}$ nanowire. The $2 \mathrm{H}$ nanodomains constitute a ratio of almost one-fifth of the total volume of the nanowire. This novel heterostructure of Ge allotropes opens new amazing multifunctionnalities of group-IV nanowires for next-generation devices. Because $3 \mathrm{C}$ and $2 \mathrm{H}$ phases have different band structures and charge densities, the presence of $3 \mathrm{C} / 2 \mathrm{H}$ heterostructures may alter significantly the electrical, thermal, and optical properties of $\mathrm{Ge}$ nanowires. Few papers have reported a direct small band gap of Ge-2H. ${ }^{49-51}$ Thus, the $3 \mathrm{C} /$ 
$2 \mathrm{H}$ heterostructure may be optically active in the mid-IR region and can be a promising candidate for IR detection. Enhanced optical emission and absorption are also expected due to confinement effects in the nanostructures. In addition, the presence of periodic boundaries between the two phases may induce a strong reduction of thermal conductivity with an almost unchanged electronic conductivity, and thus, one must expect a great enhancement of the thermoelectric figure of merit. However, to be usable, the heterostructured nanowires must be stable in operational conditions. In that way, we have studied the stability of the $\mathrm{Ge}-2 \mathrm{H}$ nanodomains in the nanowires.

Thermal Stability of $\mathbf{2 H}$ Phase. Regarding the stability of the $2 \mathrm{H}$ phase, the formed domains are stable over several months in standard ambient conditions. We have also considered their thermal stability by TEM in situ observations. Experiments were carried out with a heating holder to follow in real time the phase transformation under annealing up to 650 ${ }^{\circ} \mathrm{C}$. We used a Aduro holder and thermal E-chips from Protochips company. In Figure 9 are presented micrographs of heterostructured nanowires after successive annealings. We have performed similar experiments on almost 10 nanowires. In general, below $400{ }^{\circ} \mathrm{C}$ nanowires are not affected by thermal anneal; instabilities appear between 500 and $600{ }^{\circ} \mathrm{C}$. Some domains fully recrystallize toward the $3 \mathrm{C}$ phase (not depending on the domain size). This recrystallization can be quite sudden and appears in a small thermal range. On the contrary, other domains remain stable with the $2 \mathrm{H}$ allotropic form up to 650 ${ }^{\circ} \mathrm{C}$, but the overall nanowire evolves in size and shape (see Figure 10). It is worth noting that the nanowires exhibiting the smallest diameters sublimate under vacuum above $600{ }^{\circ} \mathrm{C}$. Thus, similar experiments must be performed while keeping the nanowires embedded in a matrix (silica for instance). Anyway, $2 \mathrm{H}$ nanodomains are stable up to $500{ }^{\circ} \mathrm{C}$.

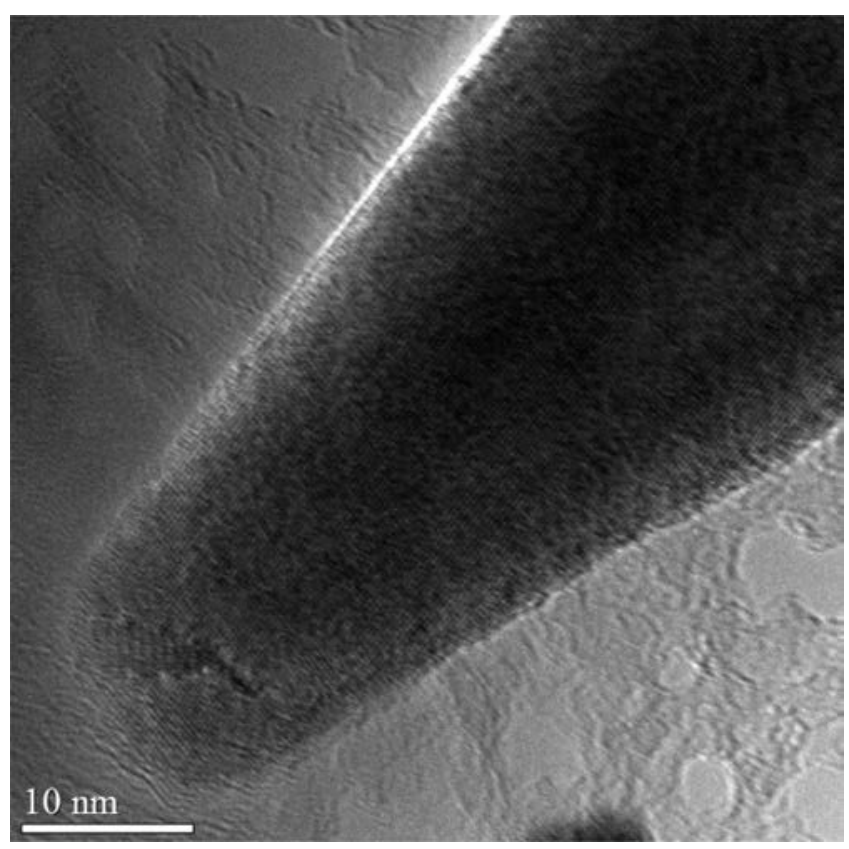

Figure 10. Nanowire from Figure 9 annealed at $650^{\circ} \mathrm{C}$. The tip of the nanowire still holds a small $2 \mathrm{H}$ nanodomain, but at this temperature, the shape and size of the nanowire has been strongly changed due to sublimation and atom surface diffusion.
Conclusion. We have developed a technological process to perform in a reproducible way a phase transformation of $\mathrm{Ge}$ toward the allotrope hexagonal diamond structure namely $2 \mathrm{H}$. This transformation is produced heterogeneously along the nanowire under small external stress at around $500{ }^{\circ} \mathrm{C}$. The resulting nanowire consists of in a quasiperiodic allotrope heterostructure with hexagonal and cubic structures along the nanowires. TEM observations give evidence of a martensitic transformation. Both parameters, stress and thermal budget above a threshold temperature of $350{ }^{\circ} \mathrm{C}$, are mandatory for this transformation. Finally, the thermal stability of the hexagonal phase was studied in situ with TEM observations.

\section{ASSOCIATED CONTENT}

\section{Supporting Information}

Nanostructuration of partially embedded Ge nanowires, and elemental concentrations given by the EDS measurements.This material is available free of charge via the Internet at http:// pubs.acs.org.

\section{AUTHOR INFORMATION}

\section{Corresponding Author}

E-mail: laetitia.vincent@ief.u-psud.fr. Phone: + 331691579 Fax: +33169154010.

\section{Notes}

The authors declare no competing financial interest.

\section{ACKNOWLEDGMENTS}

The authors are grateful to the "Centrale de Technologie Universitaire" MINERVE for technological backup and the support of RENATECH. Part of the experiments were enabled by the ANR funding (TEMPOS Equipex).

\section{REFERENCES}

(1) David, T.; Buttard, D.; Schülli, T.; Dallhuin, F.; Gentile, P. Surf. Sci. 2008, 602, 2675.

(2) Tian, B.; Xie, P.; Kempa, T. J.; Bell, D. C.; Lieber, C. M. Nat. Nano 2009, 4, 824.

(3) Boukhicha, R.; Gardès, C.; Vincent, L.; Renard, C.; Yam, V.; Fossard, F.; Patriarche, G.; Jabeen, F.; Bouchier, D. Europhys. Lett. 2011, 95, 18004.

(4) Jeon, N.; Dayeh, S. A.; Lauhon, L. J. Nano Lett. 2013, 13, 3947.

(5) Johansson, J.; Bolinsson, J.; Ek, M.; Caroff, P.; Dick, K. A. ACS Nano 2012, 6, 6142.

(6) Algra, R. E.; Verheijen, M. A.; Borgström, M. T.; Feiner, L.; Immink, G.; van Enckevort, W. J. P.; Vlieg, E.; Bakkers, E. P. A. M. Nature 2008, 456, 369.

(7) Caroff, P.; Dick, K. A.; Johansson, J.; Messing, M. E.; Deppert, K.; Samuelson, L. Nature Nanotechnol. 2009, 4, 50.

(8) Arbiol, J.; Kalache, B.; Roca, i; Cabarrocas, P.; Ramon Morante, J.; Fontcuberta, i; Morral, A. Nanotechnology 2007, 18, 305606.

(9) Algra, R. E.; Hocevar, M.; Verheijen, M. A.; Zardo, I.; Immink, G. G. W.; van Enckevort, W. J. P.; Abstreiter, G.; Kouwenhoven, L. P.; Vlieg, E.; Bakkers, E. P. A. M. Nano Lett. 2011, 11, 1690.

(10) Gogotsi, Y., Domnich, V. High Pressure Surface Science and Engineering; Taylor \& Francis: Philadelphia, PA, 2003.

(11) Wang, Y.-B.; Wang, L.-F.; Joyce, H. J.; Gao, Q.; Liao, X.-Z.; Mai, Y.-W.; Tan, H. H.; Zou, J.; Ringer, S. P.; Gao, H.-J.; Jagadish, C. Adv. Mater. 2011, 23, 1356.

(12) Zhang, Y.; Han, X.; Zheng, K.; Zhang, Z.; Zhang, X.; Fu, J.; Ji, Y.; Hao, Y.; Guo, X.; Wang, Z. L. Adv. Funct. Mater. 2007, 17, 3435.

(13) Wu, B.; Heidelberg, A.; Boland, J. J. Nat. Mater. 2005, 4, 525.

(14) Han, X. D.; Zheng, K.; Zhang, Y. F.; Zhang, X. N.; Zhang, Z.; Wang, Z. L. Adv. Mater. 2007, 19, 2112. 
(15) Zhu, Y.; Xu, F.; Qin, Q.; Fung, W. Y.; Lu, W. Nano Lett. 2009, 9, 3934

(16) Ngo, L. T.; Almécija, D.; Sader, J. E.; Daly, B.; Petkov, N.; Holmes, J. D.; Erts, D.; Boland, J. J. Nano Lett. 2006, 6, 2964.

(17) Smith, D. A.; Holmberg, V. C.; Korgel, B. A. ACS Nano 2010, 4, 2356.

(18) Jing, Y.; Meng, Q.; Gao, Y. Comput. Mater. Sci. 2009, 45, 321.

(19) Liu, Q.; Shen, S. Int. J. Plasticity 2012, 38, 146.

(20) Shankar, M. R.; King, A. H. Appl. Phys. Lett. 2007, 90, 141907.

(21) Dingreville, R. m.; Qu, J.; Mohammed, C. J. Mech. Phys. Solids

2005, 53, 1827.

(22) Pennelli, G.; Totaro, M.; Nannini, A. ACS Nano 2012, 6, 10727.

(23) Diao, J.; Gall, K.; Dunn, M. L. Nat. Mater. 2003, 2, 656.

(24) Ma, F.; Xu, K.-W.; Chu, P. K. Mater. Sci. Eng., R: Reports 2013, $74,173$.

(25) Guenole, J.; Godet, J.; Brochard, S. Modell. Simul. Mater. Sci. Eng. 2011, 19, 074003.

(26) Chiang, C. K.; Wallace, W. E.; Lynn, G. W.; Feiler, D.; Xia, W. Appl. Phys. Lett. 2000, 76, 430.

(27) Liou, H. C.; Pretzer, J. Thin Solid Films 1998, 335, 186.

(28) Yin, M. T.; Cohen, M. L. Phys. Rev. B 1982, 26, 5668.

(29) Vohra, Y. K.; Brister, K. E.; Desgreniers, S.; Ruoff, A. L.; Chang,

K. J.; Cohen, M. L. Phys. Rev. Lett. 1986, 56, 1944.

(30) Voronin, G. A.; Pantea, C.; Zerda, T. W.; Zhang, J.; Wang, L.; Zhao, Y. J. Phys. Chem. Solids 2003, 64, 2113.

(31) Qadri, S. B.; Skelton, E. F.; Webb, A. W. J. Appl. Phys. 1983, 54, 3609 .

(32) Menoni, C. S.; Hu, J. Z.; Spain, I. L. Phys. Rev. B 1986, 34, 362.

(33) Patriarche, G.; Le Bourhis, E.; Khayyat, M. M. O.; Chaudhri, M. M. J. Appl. Phys. 2004, 96, 1464.

(34) Brazhkin, V. V.; Lyapin, A. G.; Popova, S. V.; Voloshin, R. N. Phys. Rev. B 1995, 51, 7549.

(35) Haberl, B.; Guthrie, M.; Malone, B. D.; Smith, J. S.; Sinogeikin, S. V.; Cohen, M. L.; Williams, J. S.; Shen, G.; Bradby, J. E. Phys. Rev. B 2014, 89, 144111.

(36) Xiao, S. Q.; Pirouz, P. J. Mater. Res. 1992, $7 n^{\circ} 6,1406$.

(37) Zhang, Y.; Iqbal, Z.; Vijayalakshmi, S.; Qadri, S.; Grebel, H. Solid State Commun. 2000, 115, 657.

(38) Bradby, J. E.; Williams, J. S.; Wong-Leung, J.; Swain, M. V.; Munroe, P. Appl. Phys. Lett. 2002, 80, 2651.

(39) Eremenko, V. G.; Nikitenko, V. I. Physica Status Solidi A 1972, 14, 317.

(40) Pirouz, P.; Chaim, R.; Dahmen, U.; Westmacott, K. H. Acta Metall. Mater. 1990, 38, 313.

(41) Dahmen, U.; Westmacott, K. H.; Pirouz, P.; Chaim, R. Acta Metall. Mater. 1990, 38, 323.

(42) Clapp, P. C. J. Phys. IV 1995, 5, C8-11.

(43) Porter, D. A.; Easterling, K. E. Phase transformations in metals and alloys, 2nd ed.; Chapman and Hall Taylor \& Francis: Philadelphia, PA, 1992.

(44) Kelly, A. A.; Knowles, K. M. Crystallography and crystal defects, 2nd ed.; Wiley: Weinheim, Germany, 2012.

(45) Zhu, T.; Li, J.; Samanta, A.; Leach, A.; Gall, K. Phys. Rev. Lett. 2008, 100, 025502.

(46) Yang, Z.; Lu, Z.; Zhao, Y.-P. J. Appl. Phys. 2009, 106.

(47) Guénolé, J.; Brochard, S.; Godet, J. Acta Mater. 2011, 59, 7464.

(48) Park, H. S. Nano Lett. 2006, 6, 958.

(49) Joannopoulos, J. D.; Cohen, M. L. Phys. Rev. B 1973, 7, 2644.

(50) Joannopoulos, J. D.; Cohen, M. L. Phys. Rev. B 1973, 8, 2733.

(51) Malone, B. D.; Cohen, M. L. Phys. Rev. B 2012, 86, 054101. 